\title{
Inducing pluripotency in livestock somatic cells to enhance genome-editing opportunities
}

\author{
Jun $\mathrm{Liu}^{1 *}$, Amir Taheri-Ghahfarokhi ${ }^{2 *}$ and Paul John Verma ${ }^{1,3}$ \\ ${ }^{1}$ Division of Bio-Engineering, Monash University, Australia; ${ }^{2}$ Animal Science Department, Ferdowsi \\ University of Mashhad, Mashhad, Iran; ${ }^{3}$ South Australia Research and Development Institute, \\ Turretfield Research Center, Rosedale, Australia
}

\begin{abstract}
Although the manipulation of animal genomes has a history of more than three decades, there are only a few of the reported genetically modified (GM) animals that have passed safety regulations and found their way through to market. The production and safety regulations of GM livestock are hindered by a variety of issues, most importantly, lack of embryonic stem cells (ESC) in livestock species and concerns around the nature and biosafety of the genome manipulations, respectively.

As an alternative for ESC, induced pluripotent stem cells (iPSC) have reportedly been generated in livestock species. The initial attempts at generating iPSC were based on viral integration of specific factors into the genome of differentiated cells. However, attempts have been made in developing safer methods for generating virus-free iPSC. Although the possibility of inducing a pluripotency state in somatic cells raises hopes to overcome the lack of ESC in livestock, as yet there is no report on successful iPSC cell mediated transgenesis in large domestic animals.

Recent advances in genome editing exploiting site-specific endonucleases provide unprecedented potential for modifying the genome of livestock with reduction in off-target events, high efficiency and user-friendly approaches which are widely applicable across species. The high efficiencies achieved support the tantalizing prospect of achieving sophisticated genome-editing at the zygote stage even in livestock species.
\end{abstract}

\section{Introduction}

The term "transgenesis" coined by Gordon and Ruddle described a technical process enabling transfer of inheritable functional genes between organisms irrespective of species barriers (Gordon \& Ruddle 1981). The introduction, expression and transmission of novel genes has been successfully demonstrated in a number of invertebrates, including C. elegans (Stinchcomb et 
al. 1985), Drosophila (Spradling \& Rubin 1982), sea urchins (Mcmahon et al. 1984, Mcmahon et al. 1985) and lower vertebrates, frogs (Bendig 1981). Gene transfer was first reported in mammals by Jaenisch (1976), with a major advance occurring 5 years later when Palmiter et al. (1982) microinjected multiple copies of a gene construct, containing promoter elements to regulate the functioning of the introduced gene, into the pronucleus of fertilized one-cell mouse embryos, resulting in random integration into the host genome and subsequent passage via their germline to their offspring.

Following the success of transgenesis in mice the technology was transferred to a number of mammalian species (Hammer et al. 1985, Brem et al. 1986, Pursel et al. 1987, Vize et al. 1988, Murray et al. 1989, Rexroad et al. 1989). The potential for the application of this technology to livestock was huge, both from the scientific and commercial viewpoints. However technical limitations were identified with DNA injection in farm animals, including difficulty with visualizing the pronucleus, limited control over inserted copy number and random and low efficiency of integration resulting in mosiacism of the transgene presence in resulting animals (Nottle et al. 1997).

The cultivation of mouse ESC by Sir Martin Evans (1981), followed by the application of conventional HR techniques for targeting genes in $\mathrm{mESC}$, resulted in the generation of the first knockout mouse in 1989 (Evans \& Kaufman 1981, Capecchi 1989). However, this was not easily translated in livestock due the lack of true germ-line competent ESC in these species.

\section{Induction of pluripotency in livestock}

True germ-line embryonic stem cells have not yet been isolated from non-rodents, including livestock species, despite significant efforts. The unique characteristics of the ESC, if they could be generated from livestock, would make them an invaluable resource for both agricultural and biomedical applications. However, the goal of derivation of naïve (or ground state) ESC from livestock has remained elusive over the last two decades (Blomberg \& Telugu 2012). For a comprehensive review on pluripotency in livestock species see review by Malaver-Ortega (Malaver-Ortega et al. 2012).

\section{Direct reprogramming of somatic cells}

An amazing discovery in stem cell research was the generation of iPSC. The significance of the work was recognized by the joint-award of the Nobel Prize for Physiology and Medicine in 2012 to Shinya Yamanaka for its discovery. Ectopic expression of just four transcription factors, namely Oct4, Sox2, Klf4 and c-Myc in a variety of body cells resets the transcription profile and epigenetic state of the host cells to iPSC. These cell types are very much like ESC (Takahashi \& Yamanaka 2006), can be germ line competent (Okita et al. 2007) and contribute to iPSC-mice by tetraploid complementation assay (Boland et al. 2009, Zhao et al. 2009, Kang et al. 2011). In this regard, establishment of iPSC from various farm animals holds considerable promise. The technology has since been applied to successfully generate iPSC from agriculturally important species, including cattle, sheep, and pig.

Cattle

Our laboratory published the first report on the establishment of iPSC from bovine fibroblasts (Han et al. 2011, Huang et al. 2011, Sumer et al. 2011). We delivered a combination of reprogramming genes identified by Yamanaka (Oct4, Sox2, Klf4 and cMyc; designated as 
OSKM) plus Nanog, with human gene sequences, to bovine adult fibroblasts with a VSVG pantropic retroviral delivery system. The bovine iPSC generated expressed pluripotent markers, including AP, SSEA-1, REX1, Oct4 and Sox2, and stably transfected with CAG-GFP constructs as a reporter gene (Sumer et al. 2011). The bovine iPSC were also capable of forming teratomas in the immunodeficient mice, and also differentiated in vitro to the three germ layers (Sumer et al. 2011). Bovine iPSC were also generated using either a combination of OSKM, with Lin28 and Nanog (Han et al. 2011), or using a combination of OSKM with dual kinase inhibitors (PD0325901 and ChIR9902) (Huang et al. 2011).

In our hands, it has proved difficult to reprogram bovine fibroblasts using only the Yamanaka reprogramming factors OSKM, with success achieved by including additional Nanog into the reprogramming cocktail (Sumer et al. 2011). It is suggested that species-specific requirements of reprogramming factors might exist regarding the transcription factors necessary for complete reprogramming in cattle (Malaver-Ortega et al. 2012).

\section{Sheep}

Induced pluripotent stem cells have been successfully generated from sheep fibroblasts (Bao et al. 2011, Li et al. 2011, Liu et al. 2012, Sartori et al. 2012). Interestingly, Nanog, which is a critical factor for reprogramming pluripotency in bovine fibroblasts, is not a required factor to establish completely reprogrammed sheep iPSC in our studies (Liu et al. 2012). The four Yamanaka factors (OSKM) were sufficient to reprogram sheep embryonic fibroblasts (SEF) to pluripotency. We routinely use amphotropic retrovirus to transduce human fibroblasts with OSKM to generate human iPSC (Liu et al. 2010, Liu et al. 2011). However, transduction of SEF with amphotropic retrovirus was inefficient; therefore, we examined the use of pantropic retrovirus (VSV-G) to deliver the factors, which significantly increased transduction rates from 19.5 to $83.5 \%$, respectively. The sheep iPSC at passage 5 continued expression of all four transgenes. However, when the sheep iPSC were propagated to passage 12, significant downregulation of the transgene Oct4 occurred. Further, the sheep iPSC maintained pluripotency with transcriptional silencing of the four transgenes even by passage 17 . The sheep iPSC expressed endogenous Oct4, Nanog and Sox2, but did not express SSEA-1, SSEA3, SSEA4, Tra-1-60, or Tra-1-81 cell surface markers. The sheep iPSC typically grew in compact colonies, with a three-dimensional shape and distinct, glistening edge; morphology was similar to that of mouse ESC. The sheep iPSC were readily dissociated by trypsin-EDTA, which makes the cells more amenable to basic techniques desirable for creating GM sheep, such as FACS, efficient colony-cloning and blastocyst injection. Using these attributes, we successfully transfected the sheep iPSC with a CAG-GFP vector and enriched GFP expressing cells by FACS. Microinjection of GFP+ ${ }^{+}$-iPSC into ovine 8- to 16-cell stage embryos demonstrated their integration in the ICM of the resulting sheep blastocysts. Two reports have used Dox-inducible lentivirus containing either using the four OSKM factors alone (Li et al. 2011) or OSKM combined with an additional four factors (NANOG, Lin28, SV40 and hTERT) (Bao et al. 2011) to transduce sheep fibroblasts. Maintenance of the putative sheep iPSC generated in both studies was dependent on addition of Dox to the culture medium. Withdrawal of Dox resulted in transgene silencing and an associated loss of pluripotency, thus confirming that the endogenous pluripotent genes were not fully reprogrammed in the putative sheep iPSC.

\section{Pig}

The first iPSC generated from a livestock species were from the pig in 2009 (Esteban et al. 2009, Ezashi et al. 2009, Wu et al. 2009), followed by several additional porcine iPSC lines generated in 2010 and 2011 (Telugu et al. 2010, West et al. 2010, Montserrat et al. 2011). 
The porcine iPSC generated by all groups were pluripotent, as demonstrated by the potential to differentiate into tissues of the three germ layers in both in vivo and in vitro assays. Like the human ESC, the porcine iPSC were dependent upon the bFGF and activin/nodal signalling pathways, rather than LIF to maintain their pluripotency. The continued expression of the reprogramming transgene is a concern for their potential applications.

\section{Evolution of genome editing of mammals}

Retroviruses and DNA microinjection

The very first attempts at introducing a gene of interest (GOI) into the genome were based on either a retroviral mediated gene delivery system (Jaenisch 1976) or direct microinjection of transgene cassette into the zygotes (Gordon \& Ruddle 1981), with the latter approach mainly utilized for production of transgenic livestock (Hammer et al. 1985). Both methods have applicability to a wide variety of species; however, the main disadvantage with them is the random integration of the transgene into the genome and the limited ability to control the number of copies introduced into the genome. Both methods have limitations with the size of transgene that can be delivered and are unable to modify genes in their chromosomal contexts, in other words target the genome effectively. Therefore these methods are used only for inserting a gene randomly into the genome - commonly, referred to as 'gene addition', and not site-specific 'gene knock-in' for replacement of genes or disrupting specific targeted genes - commonly referred to as 'gene knock-out'. The fundamental limitation with these methods, which is the lack of the control of targeting the genomic site, was overcome by the discovery of HR techniques.

\section{Conventional homologous recombination}

In the 1980s, Mario Capecchi and Oliver Smithies showed HR could be used to specifically modify genes in mammalian cell types. Conventional HR techniques have numerous advantages compared with random integration-based methods including; (i) deletion of researcher-defined genomic sequences with concurrent insertion of an exogenous gene (knock-out and knockin) in a site targeted manner, (ii) taking full advantage of molecular biology knowledge and publically available genome sequences for adding adequate gene regulation elements onto the targeting cassette to ensure the desirable expression of GOI in live born animals and (iii) precise genome editing by introducing single nucleotide polymorphisms.

Despite these limitations, the International Knock-Out Mouse Consortium (IKOM) have recently reported that more than 15,000 out of 20,000 protein coding genes in mouse have been targeted (Brown \& Moore 2012a, Brown \& Moore 2012b). Unfortunately in livestock, however, targeting genes using conventional HR is not as easy. Due to the lack of germ-line transmission capable pluripotent cells, the well-known and established procedure of injecting targeted mouse ESC into the blastocyst to generate a targeted offspring via the chimera approach is not applicable to the livestock species. Therefore gene-targeting needed to be carried out on somatic cells and an additional cloning step was required to produce a live sheep (McCreath et al. (2000). The long generation interval in livestock, compared with rodents, is an obstacle for generating either bi-allelic mutants or modifying multiple loci. The major disadvantage of conventional HR, low efficiency, has been overcome in recent times with the development of genome engineering nucleases, which exponentially enhanced HR success rate. 
Genome Engineering Nucleases

The efficiency of gene targeting techniques greatly improved with the development of genome engineering nucleases. In chronological order of development, Zinc Finger Nucleases (ZFNs), Transcription Activator Like Effector Nucleases (TALENs) and Clustered Regulatory Inter-Spaced Palindromic Repeats (CRISPRs) are three major types of engineering nucleases that have been proven to efficiently target genes in their chromosomal contexts (Fig. 1).

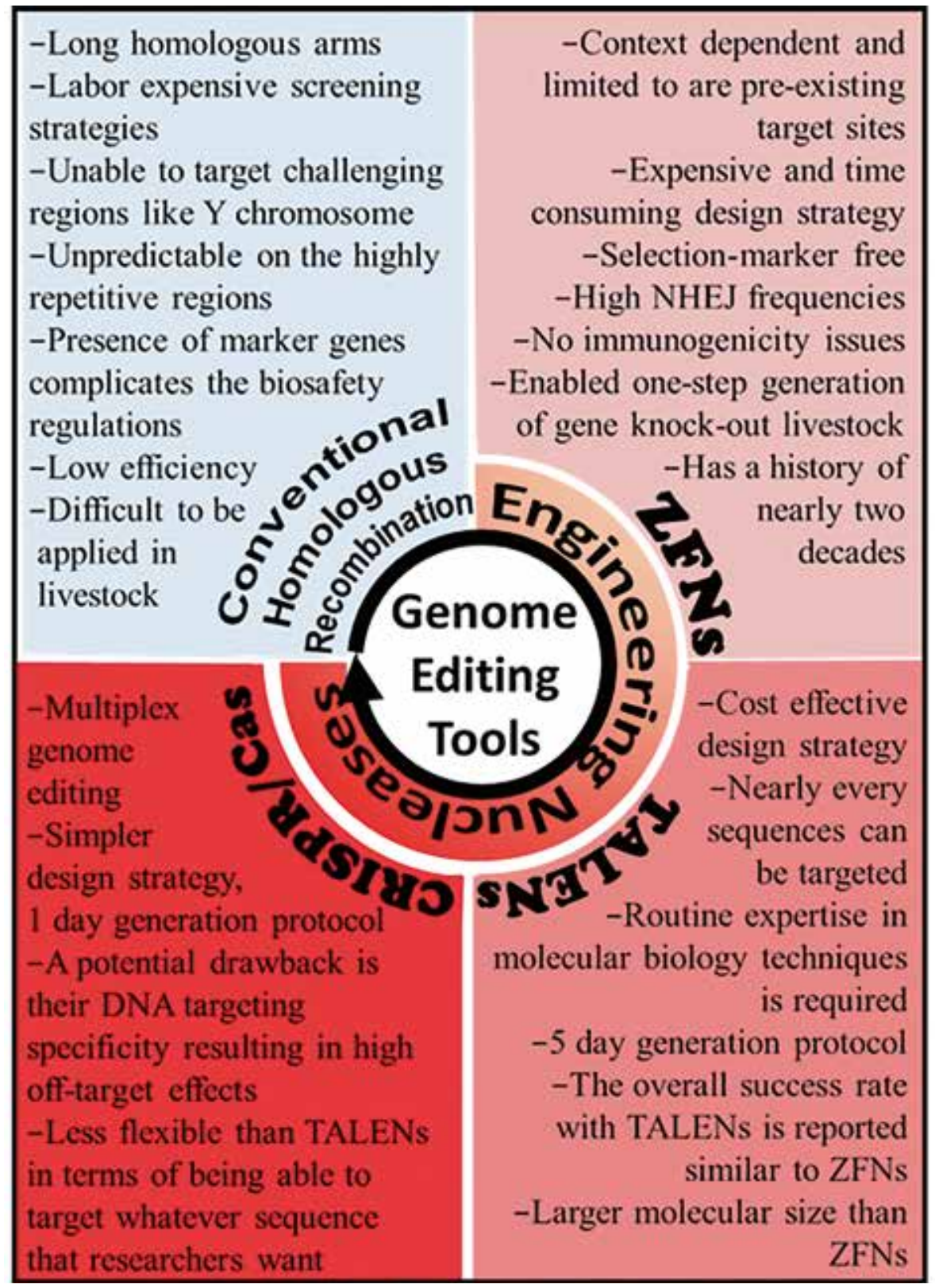

Fig. 1. Genome editing techniques demonstrating the pros and cons. 
ZFNs

Zinc finger nucleases (ZFNs) consist of a fusion of a non-specific nuclease domain of Fokl restriction endonuclease with user-defined arrays of zinc finger modules. Targeted double strand breaks (DSBs) introduced onto the DNA by ZFN dimers stimulate the DNA repair pathways. There are two main routes of DNA damage response in cells, the dominant but error prone Non-Homologous End Joining (NHEJ) and the less frequent but more precise Homology Directed Repair (HDR) pathway (Helleday et al. 2007) (Fig. 2).

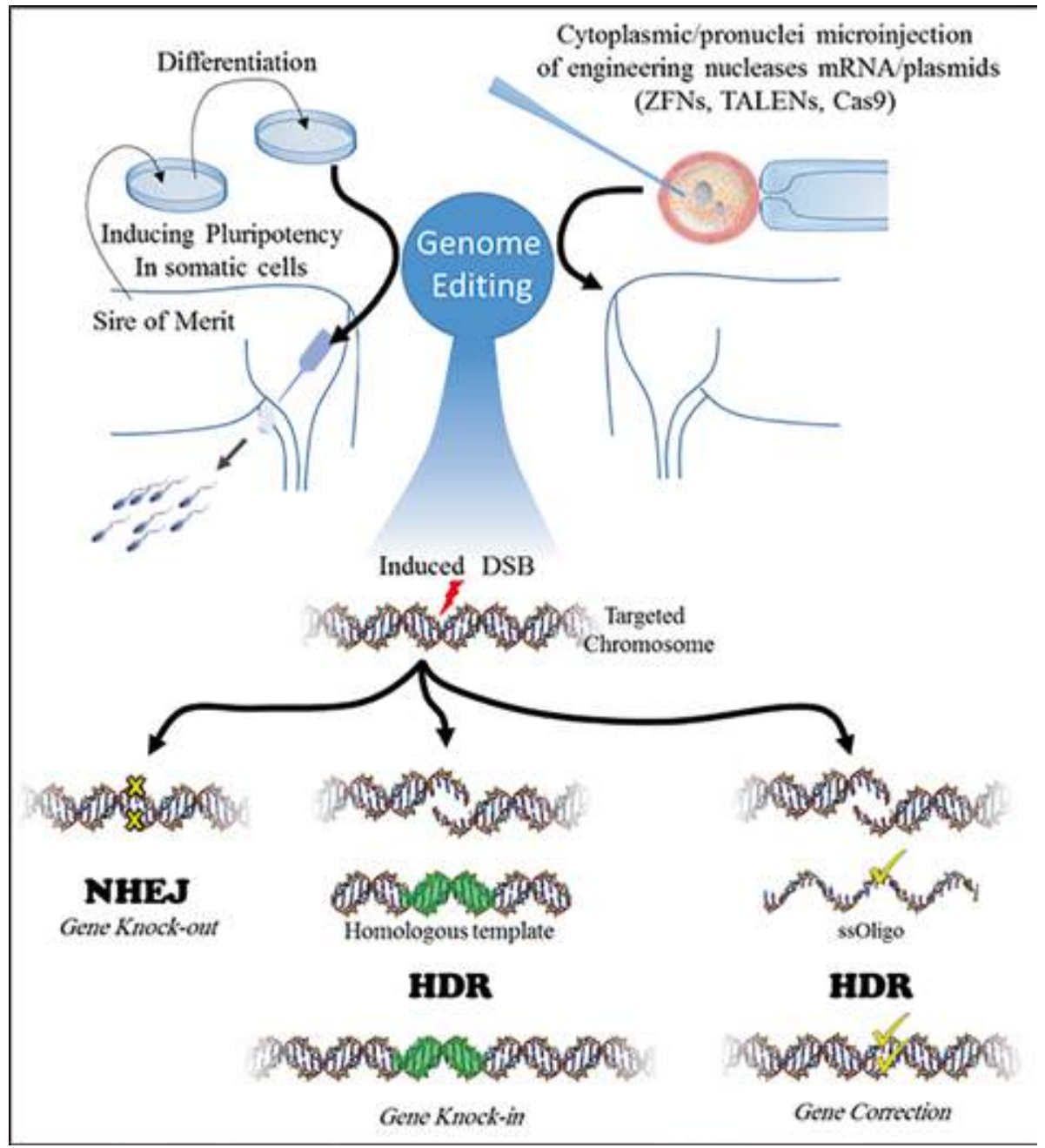

Fig. 2. Application of biotechnological state-of-the-art techniques in livestock. Genetic alteration has been facilitated by the evolution of genome editing tools.

\section{TALENS}

Despite having a short history, TALENs technology has been successfully used for targeting genes in rodents (Tong et al. 2012) and livestock (Carlson et al. 2012, Tan et al. 2013). Indeed, rapid achievements from TALENs, at least in part, are indebted to several years of pioneering research on ZFNs. 
The off-target rate of TALENs, compared with ZFNs, is less explored, however, TALENs appear to be 10-fold more mutagenic than context-dependent assembled ZFNs in zebrafish (Chen et al. 2013). More than $80 \%$ of over one hundred generated TALENs in two large-scale studies, have shown an average mutagenicity rate of $20 \%$ (Reyon et al. 2012, Chen et al. 2013). Although TALENs and ZFNs contain the same FokI nuclease domain, however they are associated with different mutation patterns at targeted loci. While ZFNs intend to induce both small insertions and deletions in nearly equal proportions, TALENs often induce deletions (Kim et al. 2013).

\section{CRISPR/Cas system}

The acquired immune system of Streptococcus pyogenes known as CRISPR/Cas system has been adopted to develop a powerful genome-editing tool, which makes use of guide RNA (gRNA) to direct Cas9 endonuclease to target sites for introducing sequence-specific DSBs (Cong et al. 2013, Mali et al. 2013b).

A potential drawback of the CRISPR/Cas system is their DNA targeting specificity (Fu et al. 2013, Hsu et al. 2013, Pattanayak et al. 2013). To reduce the off-target effects of CRISPR/ Cas system different approaches, including targeting unique sequences in the genome, using modified gRNA and Cas9 have been suggested (Cho et al. 2013, Mali et al. 2013a, Ran et al. 2013). However, it is too early to predict the ultimate impact of CRISPR/Cas technology on different aspects of life science, although, results thus far are promising and present genome engineers with a new powerful tool that has huge potential.

\section{Recent advances for enhancing gene addition experiments}

Recent advances in the genome-editing area, in addition to enhancing $\mathrm{HR}$, present additional approaches for increasing the efficiency of gene knock-in experiments.

\section{Nickases}

Engineering nucleases are highly efficient at producing knockouts by utilizing the NHEJ pathway. However, if the goal of genome editing is either gene addition or gene correction, NHEJ is not desirable because it competes with HDR and results in reduction of corrected clones. Since single-strand breaks (SSBs) or nicks cannot be repaired by the NHEJ pathway as stimulated DNA damage response by SSBs strongly bias repair toward HDR. Thus far all three types of engineering nucleases (ZFNs, TALENs and CRISPRs) that are reported to be functionally modified to introduce targeted SSBs. It has been demonstrated that ZFNickases show sufficient gene editing activity for the isolation of correct modified cells, although their gene editing activity remained lower than ZFNs (Kim et al. 2012, Ramirez et al. 2012, Wang et al. 2012). Cas9 nickase (Cas9n) also appear to efficiently target genes while having less off-target effects (Mali et al. 2013a, Ran et al. 2013). Thus, nickases-mediated gene addition approaches are much safer than use of engineering nucleases, which make targeted DSBs, due to the absence of adverse mutagenic effects.

\section{Homology-independent knock-in}

Obligation Ligation-Gated Recombination (ObLiGaRe) is described as an efficient approach for site specific gene insertion, which relies on NHEJ pathway (Maresca et al. 2013). A potential 
drawback of the ObLiGaRe approach is the integration of vector backbone, though it can be removed either with Cre or Flp recombinases or be avoided by using minicircles. Most recently, a similar homology-independent approach has been implemented for gene tagging which relies on Cas9n-mediated double nicking of the target site to create defined overhangs (Ran et al. 2013). Thus double-stranded oligonucleotides, with complementary overhangs, can effectively integrate into the target site to encode small modifications. CRISPR/Cas9-mediated DSBs also can facilitate very efficient knock-in of transgenes in a homology-independent manner (Auer et al. 2014).

\section{Foot-print free gene correction}

Transposons are jumping genes that can change their positions within the genome. The mobilization ability of transposon systems, Sleeping Beauty and piggyBac, have been used for efficient transposition of genes between vectors and chromosomes for transgenesis (Carlson et al. 2011, Macdonald et al. 2012), generating transgene-free iPSC (Yusa et al. 2009). Most interestingly, the piggyBac transposon system can be used as a foot-print free tools specially applicable for gene correction (Yusa et al. 2011, Yusa 2013).

\section{Genome editing methods}

Unlike mouse, genome modified livestock are not only useful in biomedical research, but also they can be utilized in agriculture with potential commercial impact. Although livestock such as cattle, sheep, goat and pig are much closer genetically to people than rodents for mimicking human diseases, due to the numerous limitations with manipulating their genomes these species have been employed less than rodents for generating human disease models. Still GM livestock hold promise for providing tissues for xenotransplantation and producing therapeutics. So far, several GM livestock have been created that have potential impact on agriculture, the environment and animal welfare including: mastitis- and 'mad-cow-resistant' cattle (Wall et al. 2005, Richt et al. 2007), goats and cows that produce milk with altered composition (Maga et al. 2006, Kang et al. 2011, Jabed et al. 2012), fast growing salmon (Du et al. 1992), influenza resistant chickens (Lyall et al. 2011) and maybe in the near future double-muscled and Polled dairy cattle (Tan et al. 2013). Currently however, only transgenic salmon is close to passing the FDA approval process (Ledford 2013).

\section{Genome editing zygotes (for random integration)}

A number of approaches have been investigated to transfer transgenes into the genome of animals at the zygote stage, with varying degrees of success.

\section{Pro-nuclear Microinjection}

Microinjection of transgene constructs into the male pronucleus of a zygote (Palmiter et al. 1982) is still one of the most widely used techniques for delivering transgene constructs to produce transgenic animals. It has proven useful for both commercial and research purposes. 
Sperm Mediate Gene Transfer (SMGT)

Another method that has promised much,but has yet to deliver was reported by Lavitrano et al. (Lavitrano et al. 1989). The use of sperm cells to transfer viral DNA into eggs was first described by Brackett et al. (Brackett et al. 1971). Despite the phenomenon being verified for a number of species including sea urchin (Arezzo 1989), pigs (Lavitrano et al. 1997), bulls, ram, goat, rooster, mouse and carp (Castro et al. 1990), blowfly and honey bee (Atkinson et al. 1991), no germline transgenic animals have resulted. Other variations of sperm mediated transfer that have been attempted is either the treatment of the sperm with liposomes (Bachiller et al. 1991) or electroporation of the sperm (Gagne et al. 1991, Muller et al. 1992) to facilitate uptake of DNA.

\section{Targeted genome editing using pluripotent cells}

Procedures of choice are based on ESC which allow manipulation (mutation) of resident genes in situ (Robertson 1986) and the insertion of transgenes into specific sites through homologous recombination (Capecchi 1989). Mouse iPSC resemble mouse ESC in morphology, gene expression profiles and epigenetic status (Stadtfeld et al. 2008, Wernig et al. 2008).

In the absence of robust ESC, the generation of iPSC might offer an alternative for livestock. The obvious motivating aims for the generation of iPSC, in lieu of ESC, are 1) gene targeting to perform locus-specific genetic modifications and 2) passing on the genetic alternations to the next generations through germ line transmission. However, with the advent of the TALENs and CRISPR/Cas9 system genome editing can be achieved biallelically in one round of gene targeting in zygotes of livestock, making the requirement of iPSC less critical. In addition to zygotes, somatic cells can be genetically altered similarly with site-specific nucleases and can be used as donor cells for SCNT (Carlson et al. 2012, Tan et al. 2013). Nevertheless, it remains to be determined whether using iPSC will make the same targeting events using TALEN and CRISPR/Cas9 more efficient in producing viable offspring by nuclear transfer. It has been reported that cloned piglets have been born using iPSC as donor cells, although this may not be critical because of the persistent expression of reprogramming transgenes (Fan et al. 2013).

\section{Direct targeted genome editing in embryos by DNA/RNA injection}

Simultaneous generation of GM model organisms, such as mice (Wang et al. 2013, Wefers et al. 2013), rats (Geurts et al. 2009, Tesson et al. 2011, Qiu et al. 2013) and rabbits (Yang et al. 2012) as well as livestock (Hauschild et al. 2011, Carlson et al. 2012) carrying knock-out genes, have been achieved by direct microinjection of either DNA or mRNA of engineered nucleases (ZFNs, TALENs and CRISPR/Cas system) into pronuclear-stage embryos. The activity of custom designed TALENs and CRISPR/Cas system in embryo-based gene targeting experiments has approached 90\% in mice (Wang et al. 2013) and nearly 100\% in zebrafish (Dahlem et al. 2012, Bedell et al. 2013). Various factors can affect the success rate of experiments aimed at the direct modification of zygotic genomes. Cytoplasmic microinjection of custom designed nucleases has used mRNA as it has a higher success rate than pronucleus DNA microinjection for generating knock-out rats (Tesson et al. 2011, Mali et al. 2013a). It has been demonstrated that, in a dose dependent response, direct microinjection of different concentrations of TALENs into embryos varying mutagenesis frequencies are achieved and produce a different percentage of bi-allelic knock-outs, as well as variations in the blast formation rate (Carlson et al. 2012, 
Wang et al. 2013). To enrich modified embryos, mRNA/DNA encoding fluorescent proteins, like EGFP, can be co-injected with engineering nucleases (Carlson et al. 2012). The mutations generated by all three types of custom designed nucleases in founder animals can be efficiently transmited to the offspring (Cui et al. 2011, Mali et al. 2013a, Qiu et al. 2013, Sung et al. 2013). One-step generated GM founders also can result in mosaic animals (Wang et al. 2013) and therefore offspring of the founder animals needs to be genotyped.

\section{Conclusions}

Concerns around the genetic manipulation of animal genomes and the safety of their products has been the subject of increasing discussion between opponents and proponents of animal transgenesis including researchers, policy makers and the public. Proponents argue that GM animals hold great promise for improved animal welfare, healthier food, less environmental impact and as the production of human drugs. However, concerns arise around the biosafety of techniques used for generating GM animals. In this review we have presented our perspective on the advances made for inducing pluripotency and progress in genome editing., The progress made to date should help to address both the technical and biosafety issues in generating GM livestock.

Site-specific nucleases are closest to presenting genome-engineering researchers with an ideal DNA microsurgery tool. The best potential features the use of engineering nucleases which can be summarized as having the least effects, highest efficiency, marker-free selection, nontoxic, cost efficient, user-friendly protocol and being widely applicable across different species. All of these properties would enable significant progress for achieving farm animals with improved genetic makeup, consistent with regulatory guidelines for GM livestock. In addition, being able to target genes in early stage embryos, by injecting the engineering nucleases into either the cytoplasmic or pronuclear space, is extremely important for livestock because as yet there is no germline transmission capable of producing pluripotent stem cells. Although direct genome modification of zygotes appears to be highly efficient in rodents, somatic cell genome editing, followed by cloning, would be extremely useful in large animals, due to small litter size of these animals and to avoid increased gestation costs in these species.

Although the recent advances in genome editing will rapidly increase the use of livestock biotechnology in a variety of applications, thus far, the majority of genes that have been targeted in livestock species are also genes with potential applications in human health (Bruce et al. 2013). Furthermore, as the efficiency of the process improves even further the application of these approaches for modulating and enhancing livestock for production and welfare gain is becoming exceedingly feasible, hence the increasing excitement in the field.

\section{References}

Arezzo F 1989 Sea-urchin sperm as a vector of foreign genetic information. Cell Biology International Reports 13 391-404.

Atkinson PW, Hines ER, Beaton S, Matthaei KI, Reed KC \& Bradley MP 1991 Association of exogenous DNA with cattle and insect spermatozoa invitro. Molecular Reproduction and Development 29 1-5.

Auer TO, Duroure K, De Cian A, Concordet J-P \& Del Bene F 2014 Highly efficient crispr/cas9-mediated knock-in in zebrafish by homology-independent DNA repair. Genome Research 24 142-153.

Bachiller D, Schellander K, Peli J \& Ruther U 1991 Liposome-mediated DNA uptake by sperm cells. Molecular Reproduction and Development 30 194200.

Bao L, He L, Chen J, Wu Z, Liao J, Rao L, Ren J, Li H, Zhu H, Qian L, Gu Y, Dai H, Xu X, Zhou J, Wang W, Cui C \& Xiao L 2011 Reprogramming of ovine adult 
fibroblasts to pluripotency via drug-inducible expression of defined factors. Cell Research 21 600-608.

Bedell VM, Wang Y, Campbell JM, Poshusta TL, Starker CG, Krug li RG, Tan W, Penheiter SG, Ma AC, Leung AYH, Fahrenkrug SC, Carlson DF, Voytas DF, Clark KJ, Essner JJ \& Ekker SC 2013 In vivo genome editing using a highefficiency talen system. Nature 491 114-118.

Bendig MM 1981 Persistence and expression of histone genes injected into xenopus eggs in early development. Nature 292 65-67.

Blomberg LA \& Telugu BP 2012 Twenty years of embryonic stem cell research in farm animals. Reproduction in Domestic Animals 47 80-85.

Boland MJ, Hazen JL, Nazor KL, Rodriguez AR, Gifford W, Martin G, Kupriyanov S \& Baldwin KK 2009 Adult mice generated from induced pluripotent stem cells. Nature 461 91-94.

Brackett BG, Baranska W, Sawicki W \& Koprowski H 1971 Uptake of heterologous genome by mammalian spermatozoa and its transfer to ova through fertilization. Proceedings of the National Academy of Sciences of the United States of America 68 353-357.

Brem G, Brenig B, Goodman HM, Selden RC, Graf F, Kruff B, Springmann K, Meyer J, Winnacker EL \& Krausslich H 1986 Production of transgenic mice, rabbits and pigs by microinjection. Theriogenology 25 143-143.

Brown SD \& Moore MW 2012a The international mouse phenotyping consortium: Past and future perspectives on mouse phenotyping. Mammalian Genome 23 632-640.

Brown SDM \& Moore MW 2012b Towards an encyclopaedia of mammalian gene function: The international mouse phenotyping consortium. Disease Models \& Mechanisms 5 289-292.

Bruce A, Castle D, Gibbs C, Tait J \& Whitelaw CBA 2013 Novel gm animal technologies and their governance. Transgenic research 22 681-695.

Capecchi MR 1989 Altering the genome by homologous recombination. Science 244 1288-1292.

Carlson DF, Garbe JR, Tan W, Martin MJ, Dobrinsky JR, Hackett PB, Clark KJ \& Fahrenkrug SC 2011 Strategies for selection marker-free swine transgenesis using the sleeping beauty transposon system. Transgenic research 20 1125-1137.

Carlson DF, Tan W, Lillico SG, Stverakova D, Proudfoot C, Christian M, Voytas DF, Long CR, Whitelaw CB \& Fahrenkrug SC 2012 Efficient talen-mediated gene knockout in livestock. Proceedings of the National Academy of Sciences of the United States of America 109 17382-17387.

Castro FO, Hernandez O, Uliver C, Solano R, Milanes C, Aguilar A, Perez A, Dearmas R, Herrera L \& Delafuente J 1990 Introduction of foreign DNA into the spermatozoa of farm-animals. Theriogenology 34 1099-1110.

Chen S, Oikonomou G, Chiu CN, Niles BJ, Liu J, Lee DA, Antoshechkin I \& Prober DA 2013 A large-scale in vivo analysis reveals that talens are significantly more mutagenic than zfns generated using context-dependent assembly. Nucleic Acids Research 41 2769-2778.

Cho SW, Kim S, Kim Y, Kweon J, Kim HS, Bae S \& Kim J-S 2013 Analysis of off-target effects of crispr/cas-derived rna- guided endonucleases and nickases. Genome Research 24 132-141.

Cong L, Ran FA, Cox D, Lin S, Barretto R, Habib N, Hsu PD, Wu X, Jiang W \& Marraffini LA 2013 Multiplex genome engineering using crispr/cas systems. Science 339 819-823.

Cui X, Ji D, Fisher DA, Wu Y, Briner DM \& Weinstein EJ 2011 Targeted integration in rat and mouse embryos with zinc-finger nucleases. Nature Biotechnology 29 64-67.

Dahlem TJ, Hoshijima K, Jurynec MJ, Gunther D, Starker CG, Locke AS, Weis AM, Voytas DF \& Grunwald DJ 2012 Simple methods for generating and detecting locusspecific mutations induced with talens in the zebrafish genome. PLoS Genetics 8 e1002861.

Du SJ, Gong ZY, Fletcher GL, Shears MA, King MJ, Idler DR \& Hew CL 1992 Growth enhancement in transgenic atlantic salmon by the use of an "all fish" chimeric growth hormone gene construct. Biotechnology 10 176-181.

Esteban MA, Xu J, Yang J, Peng M, Qin D, Li W, Jiang Z, Chen J, Deng K, Zhong M, Cai J, Lai L \& Pei D 2009 Generation of induced pluripotent stem cell lines from tibetan miniature pig. Journal of biological chemistry 284 17634-17640.

Evans MJ \& Kaufman MH 1981 Establishment in culture of pluripotential cells from mouse embryos. Nature 292 154-156.

Ezashi T, Telugu BP, Alexenko AP, Sachdev S, Sinha S \& Roberts RM 2009 Derivation of induced pluripotent stem cells from pig somatic cells. Proceedings of the National Academy of Sciences of the United States of America 106 10993-10998.

Fan N, Chen J, Shang Z, Dou H, Ji G, Zou Q, Wu L, He L, Wang F, Liu K, Liu N, Han J, Zhou Q, Pan D, Yang D, Zhao B, Ouyang Z, Liu Z, Zhao Y, Lin L, Zhong C, Wang Q, Wang S, Xu Y, Luan J, Liang Y, Yang Z, Li J, Lu C, Vajta G, Li Z, Ouyang H, Wang H, Wang Y, Yang Y, Liu Z, Wei H, Luan Z, Esteban M, Deng H, Yang H, Pei D, Li N, Pei G, Liu L, Du Y, Xiao L \& Lai L 2013 Piglets cloned from induced pluripotent stem cells. Cell Research 23 162-166.

Fu Y, Foden JA, Khayter C, Maeder ML, Reyon D, Joung JK \& Sander JD 2013 High-frequency off-target mutagenesis induced by crispr-cas nucleases in human cells. Nature Biotechnology 31 822-826.

Gagne MB, Pothier F \& Sirard MA 1991 Electroporation of bovine spermatozoa to carry foreign DNA in oocytes. Molecular Reproduction and Development 29 6-15.

Geurts AM, Cost GJ, Freyvert Y, Zeitler B, Miller JC, Choi VM, Jenkins SS, Wood A, Cui X, Meng X, Vincent A, Lam S, Michalkiewicz M, Schilling R, Foeckler J, Kalloway S, Weiler H, Menoret S, Anegon I, Davis GD, Zhang L, Rebar EJ, Gregory PD, Urnov FD, Jacob HJ \& Buelow R 2009 Knockout rats via embryo microinjection of zincfinger nucleases. Science 325433.

Gordon JW \& Ruddle FH 1981 Integration and stable germ line transmission of genes injected into mouse pronuclei. Science 214 1244-1246.

Hammer RE, Pursel VG, Rexroad CE, Jr., Wall RJ, Bolt DJ, Ebert KM, Palmiter RD \& Brinster RL 1985 Production of transgenic rabbits, sheep and pigs by microinjection. Nature 315 680-683. 
Han X, Han J, Ding F, Cao S, Lim SS, Dai Y, Zhang R, Zhang Y, Lim B \& Li N 2011 Generation of induced pluripotent stem cells from bovine embryonic fibroblast cells. Cell Research 21 1509-1512.

Hauschild J, Petersen B, Santiago Y, Queisser A-L, Carnwath JW, Lucas-Hahn A, Zhang L, Meng X, Gregory PD \& Schwinzer R 2011 Efficient generation of a biallelic knockout in pigs using zinc-finger nucleases. Proceedings of the National Academy of Sciences of the United States of America 108 12013-12017.

Helleday T, Lo J, van Gent DC \& Engelward BP 2007 DNA double-strand break repair: From mechanistic understanding to cancer treatment. DNA Repair 6 923-935.

Hsu PD, Scott DA, Weinstein JA, Ran FA, Konermann S, Agarwala V, Li Y, Fine EJ, Wu X \& Shalem O 2013 DNA targeting specificity of rna-guided cas 9 nucleases. Nature Biotechnology 31 827-832.

Huang B, Li T, Alonso-Gonzalez L, Gorre R, Keatley S, Green A, Turner P, Kallingappa PK, Verma V \& Oback B 2011 A virus-free poly-promoter vector induces pluripotency in quiescent bovine cells under chemically defined conditions of dual kinase inhibition. PLoS One 6 e24501.

Jabed A, Wagner S, McCracken J, Wells DN \& Laible G 2012 Targeted microrna expression in dairy cattle directs production of beta-lactoglobulin-free, high-casein milk. Proceedings of the National Academy of Sciences of the United States of America 109 16811-16816.

Jaenisch R 1976 Germ line integration and mendelian transmission of the exogenous moloney leukemia virus. Proceedings of the National Academy of Sciences of the United States of America 73 1260-1264.

Kang L, Wu T, Tao Y, Yuan Y, He J, Zhang Y, Luo T, Kou Z \& Gao S 2011 Viable mice produced from three-factor induced pluripotent stem (ips) cells through tetraploid complementation. Cell Research 21 546-549.

Kim E, Kim S, Kim DH, Choi B-S, Choi I-Y \& Kim J-S 2012 Precision genome engineering with programmable DNAnicking enzymes. Genome Research 22 1327-1333.

Kim Y, Kweon J \& Kim J-S 2013 Talens and zfns are associated with different mutation signatures. Nature Methods $\mathbf{1 0}$ 185-185.

Lavitrano M, Camaioni A, Fazio VM, Dolci S, Farace MG \& Spadafora C 1989 Sperm cells as vectors for introducing foreign DNA into eggs: Genetic transformation of mice. Cell 57 717-723.

Lavitrano M, Forni M, Varzi V, Pucci L, Bacci ML, Di Stefano C, Fioretti D, Zoraqi G, Moioli B, Rossi M, Lazzereschi D, Stoppacciaro A, Seren E, Alfani D, Cortesini R \& Frati L 1997 Sperm-mediated gene transfer: Production of pigs transgenic for a human regulator of complement activation. Transplantation Proceedings 29 3508-3509.

Ledford H 2013 Transgenic salmon nears approval. Nature 497 17-18.

Li Y, Cang M, Lee AS, Zhang K \& Liu D 2011 Reprogramming of sheep fibroblasts into pluripotency under a druginducible expression of mouse-derived defined factors. PLoS One 6 e15947.

Liu J, Balehosur D, Murray B, Kelly JM, Sumer H \& Verma PJ 2012 Generation and characterization of reprogrammed sheep induced pluripotent stem cells. Theriogenology 77 338-346 e331.

Liu J, Sumer H, Leung J, Upton K, Dottori M, Pebay A \& Verma PJ 2010 Late passage human fibroblasts induced to pluripotency are capable of directed neuronal differentiation. Cell Transplantation 20 193-203.

Liu J, Verma PJ, Evans-Galea MV, Delatycki MB, Michalska A, Leung J, Crombie D, Sarsero JP, Williamson R, Dottori M \& Pebay A 2011 Generation of induced pluripotent stem cell lines from friedreich ataxia patients. Stem Cell Reviews 7 703-713.

Lyall J, Irvine RM, Sherman A, McKinley TJ, Núñez A, Purdie A, Outtrim L, Brown IH, Rolleston-Smith G, Sang H \& Tiley L 2011 Suppression of avian influenza transmission in genetically modified chickens. Science 331 223-226.

Macdonald J, Taylor L, Sherman A, Kawakami K, Takahashi Y, Sang HM \& McGrew MJ 2012 Efficient genetic modification and germ-line transmission of primordial germ cells using piggybac and tol 2 transposons. Proceedings of the National Academy of Sciences of the United States of America 109 E1466-E1472.

Maga EA, Shoemaker CF, Rowe JD, Bondurant RH, Anderson GB \& Murray JD 2006 Production and processing of milk from transgenic goats expressing human lysozyme in the mammary gland. Journal of Dairy Science 89 518-524.

Malaver-Ortega LF, Sumer H, Liu J \& Verma PJ 2012 The state of the art for pluripotent stem cells derivation in domestic ungulates. Theriogenology 78 1749-1762.

Mali P, Aach J, Stranges PB, Esvelt KM, Moosburner M, Kosuri S, Yang L \& Church GM 2013a Cas9 transcriptional activators for target specificity screening and paired nickases for cooperative genome engineering. Nature Biotechnology 31 833-838.

Mali P, Yang L, Esvelt KM, Aach J, Guell M, DiCarlo JE, Norville JE \& Church GM 2013b Rna-guided human genome engineering via cas9. Science 339 823-826.

Maresca M, Lin VG, Guo N \& Yang Y 2013 Obligate ligation-gated recombination (obligare): Customdesigned nuclease-mediated targeted integration through nonhomologous end joining. Genome Research 23 539-546.

McCreath KJ, Howcroft J, Campbell KH, Colman A, Schnieke AE \& Kind AJ 2000 Production of gene-targeted sheep by nuclear transfer from cultured somatic cells. Nature 405 1066-1069.

Mcmahon AP, Flytzanis CN, Houghevans BR, Katula KS, Britten RJ \& Davidson EH 1985 Introduction of cloned DNA into sea-urchin egg cytoplasm - replication and persistence during embryogenesis. Developmental Biology 108 420-430.

Mcmahon AP, Novak TJ, Britten RJ \& Davidson EH 1984 Inducible expression of a cloned heat-shock fusion gene in sea-urchin embryos. Proceedings of the National Academy of Sciences of the United States of America 81 7490-7494.

Montserrat N, Bahima EG, Batlle L, Hafner S, Rodrigues AM, Gonzalez F \& Izpisua Belmonte JC 2011 Generation of pig ips cells: A model for cell therapy. Journal of Cardiovascular Translational Research 4 121-130. 
Muller F, Ivics Z, Erdelyi F, Papp T, Varadi L, Horvath L, Maclean N \& Orban L 1992 Introducing foreign genes into fish eggs with electroporated sperm as a carrier. Molecular Marine Biology and Biotechnology 1 276-281.

Murray JD, Nancarrow CD, Marshall JT, Hazelton IG \& Ward KA 1989 Production of transgenic merino sheep by microinjection of ovine metallothionein-ovine growth hormone fusion genes. Reproduction, Fertility and Development 1 147-155.

Nottle MB, Nagashima H, Verma PJ, Du ZT, Grupen CG, Ashman RJ \& Macllfatrick S 1997 Developments in transgenic techniques in pigs. Journal of Reproduction and Fertility 52 237-244.

Okita K, Ichisaka T \& Yamanaka S 2007 Generation of germline-competent induced pluripotent stem cells. Nature 448 313-317.

Palmiter RD, Brinster RL, Hammer RE, Trumbauer ME, Rosenfeld MG, Birnberg NC \& Evans RM 1982 Dramatic growth of mice that develop from eggs microinjected with metallothionein-growth hormone fusion genes. Nature 300 611-615.

Pattanayak V, Lin S, Guilinger JP, Ma E, Doudna JA \& Liu DR 2013 High-throughput profiling of off-target DNA cleavage reveals rna-programmed cas9 nuclease specificity. Nature Biotechnology 31 839-843.

Pursel VG, Rexroad CE, Jr., Bolt DJ, Miller KF, Wall RJ, Hammer RE, Pinkert CA, Palmiter RD \& Brinster RL 1987 Progress on gene transfer in farm animals. Veterinary Immunology and Immunopathology 17 303-312.

Qiu Z, Liu M, Chen Z, Shao Y, Pan H, Wei G, Yu C, Zhang L, Li X, Wang P, Fan H-Y, Du B, Liu B, Liu M \& Li D 2013 High-efficiency and heritable gene targeting in mouse by transcription activator-like effector nucleases. Nucleic Acids Research 41 e120.

Ramirez CL, Certo MT, Mussolino C, Goodwin MJ, Cradick TJ, McCaffrey AP, Cathomen T, Scharenberg AM \& Joung JK 2012 Engineered zinc finger nickases induce homology-directed repair with reduced mutagenic effects. Nucleic Acids Research 40 5560-5568.

Ran F, Hsu PD, Lin C-Y, Gootenberg JS, Konermann S, Trevino AE, Scott DA, Inoue A, Matoba S \& Zhang Y 2013 Double nicking by rna-guided crispr cas9 for enhanced genome editing specificity. Cell 154 13801389.

Rexroad CE, Jr., Hammer RE, Bolt DJ, Mayo KE, Frohman LA, Palmiter RD \& Brinster RL 1989 Production of transgenic sheep with growth-regulating genes. Molecular Reproduction and Development 1 164-169.

Reyon D, Tsai SQ, Khayter C, Foden JA, Sander JD \& Joung JK 2012 Flash assembly of talens for high-throughput genome editing. Nature Biotechnology 30 460-465.

Richt JA, Kasinathan P, Hamir AN, Castilla J, Sathiyaseelan T, Vargas F, Sathiyaseelan J, Wu H, Matsushita H, Koster J, Kato S, Ishida I, Soto C, Robl JM \& Kuroiwa Y 2007 Production of cattle lacking prion protein. Nature Biotechnology 25 132-138.

Robertson EJ 1986 Pluripotential stem-cell lines as a route into the mouse germ line. Trends in Genetics 2 9-13.

Sartori C, DiDomenico Al, Thomson AJ, Milne E, Lillico SG, Burdon TG \& Whitelaw CB 2012 Ovine-induced pluripotent stem cells can contribute to chimeric lambs. Cell Reprogramming 14 8-19.

Spradling AC \& Rubin GM 1982 Transposition of cloned p elements into drosophila germ line chromosomes. Science 218 341-347.

Stadtfeld M, Maherali N, Breault DT \& Hochedlinger K 2008 Defining molecular cornerstones during fibroblast to ips cell reprogramming in mouse. Cell Stem Cell 2 230-240.

Stinchcomb DT, Shaw JE, Carr SH \& Hirsh D 1985 Extrachromosomal DNA transformation of caenorhabditis elegans. Molecular and Cellular Biology 5 3484-3496.

Sumer H, Liu J, Malaver-Ortega LF, Lim ML, Khodadadi K \& Verma PJ 2011 Nanog is a key factor for induction of pluripotency in bovine adult fibroblasts. Journal of Animal Science 89 2708-2716.

Sung YH, Baek IJ, Kim DH, Jeon J, Lee J, Lee K, Jeong D, Kim JS \& Lee HW 2013 Knockout mice created by talenmediated gene targeting. Nature Biotechnology 31 23-24.

Takahashi K \& Yamanaka S 2006 Induction of pluripotent stem cells from mouse embryonic and adult fibroblast cultures by defined factors. Cell 126 663-676.

Tan W, Carlson D, Lancto C, Garbe J, Webster D, Hackett P \& Fahrenkrug S 2013 Efficient nonmeiotic allele introgression in livestock using custom endonucleases. Proceedings of the National Academy of Sciences of the United States of America 110 16526-16531.

Telugu BP, Ezashi T \& Roberts RM 2010 Porcine induced pluripotent stem cells analogous to naive and primed embryonic stem cells of the mouse. International Journal of Developmental Biology 54 1703-1711.

Tesson L, Usal C, Ménoret S, Leung E, Niles BJ, Remy S, Santiago Y, Vincent Al, Meng X \& Zhang L 2011 Knockout rats generated by embryo microinjection of talens. Nature Biotechnology 29 695-696.

Tong C, Huang G, Ashton C, Wu H, Yan H \& Ying Q-L 2012 Rapid and cost-effective gene targeting in rat embryonic stem cells by talens. Journal of Genetics and Genomics 39 275-280.

Vize PD, Michalska AE, Ashman R, Lloyd B, Stone BA, Quinn P, Wells JR \& Seamark RF 1988 Introduction of a porcine growth hormone fusion gene into transgenic pigs promotes growth. Journal of Cell Science 90 295-300.

Wall RJ, Powell AM, Paape MJ, Kerr DE, Bannerman DD, Pursel VG, Wells KD, Talbot N \& Hawk HW 2005 Genetically enhanced cows resist intramammary staphylococcus aureus infection. Nature Biotechnology 23 445-451.

Wang H, Yang H, Shivalila CS, Dawlaty MM, Cheng AW, Zhang F \& Jaenisch R 2013 One-step generation of mice carrying mutations in multiple genes by crispr/ cas-mediated genome engineering. Cell 153 910-918.

Wang J, Friedman G, Doyon Y, Wang NS, Li CJ, Miller JC, Hua KL, Yan JJ, Babiarz JE \& Gregory PD 2012 Targeted gene addition to a predetermined site in the human genome using a zfn-based nicking enzyme. Genome Research 22 1316-1326.

Wefers B, Meyer M, Ortiz O, Hrabé de Angelis M, Hansen J, Wurst W \& Kühn R 2013 Direct production of mouse disease models by embryo microinjection of talens and oligodeoxynucleotides. Proceedings of the National 
Academy of Sciences of the United States of America 110 3782-3787.

Wernig M, Meissner A, Cassady JP \& Jaenisch R 2008 C-myc is dispensable for direct reprogramming of mouse fibroblasts. Cell Stem Cell 2 10-12.

West FD, Terlouw SL, Kwon DJ, Mumaw JL, Dhara SK, Hasneen K, Dobrinsky JR \& Stice SL 2010 Porcine induced pluripotent stem cells produce chimeric offspring. Stem Cells and Development 19 1211-1220.

Wu Z, Chen J, Ren J, Bao L, Liao J, Cui C, Rao L, Li H, Gu Y, Dai H, Zhu H, Teng X, Cheng L \& Xiao L 2009 Generation of pig induced pluripotent stem cells with a drug-inducible system. Journal of Molecular Cell Biology 1 46-54.

Yang D, Zhang J, Xu J, Zhu T, Fan Y, Fan J \& Chen Y 2012 Production of apolipoprotein c-iii knockout rabbits using zinc finger nucleases. Journal of Visualized Experiments.
Yusa K 2013 Seamless genome editing in human pluripotent stem cells using custom endonuclease-based gene targeting and the piggybac transposon. Nature Protocols 8 2061-2078.

Yusa K, Rad R, Takeda J \& Bradley A 2009 Generation of transgene-free induced pluripotent mouse stem cells by the piggybac transposon. Nature Methods 6 363-369.

Yusa K, Rashid ST, Strick-Marchand H, Varela I, Liu P-Q, Paschon DE, Miranda E, Ordóñez A, Hannan NR \& Rouhani FJ 2011 Targeted gene correction of [agr] 1 -antitrypsin deficiency in induced pluripotent stem cells. Nature 478 391-394.

Zhao XY, Li W, Lv Z, Liu L, Tong M, Hai T, Hao J, Guo CL, Ma QW, Wang L, Zeng F \& Zhou Q 2009 Ips cells produce viable mice through tetraploid complementation. Nature 461 86-90. 